\title{
Prevalence of Cleft Lip and Palate in Abuja Nigeria (From December2000 to December 2010)
}

\author{
Abue, $\mathrm{AD}^{1}$, Nwachukwu, $\mathrm{MI}^{2}$, Aniah, $\mathrm{JA}^{3}$ andAyang, $\mathrm{U}^{4}$ \\ 1,3,4 (Department of anatomical sciences, College of health sciences, University of Abuja,Nigeria) \\ ${ }^{2}$ (Department of anatomy, college of medicine, university of Lagos)
}

\begin{abstract}
The prevalence of cleft lip and palate in University of Abuja Teaching Hospital from December 2000 to December 2010 was investigated in this works and was found to be 3.2 in every 1,000 live birth. This is very high as compared to reports from earlier works but was suspected to be due to the smile Train Project which is a private sector driven initiative that takes up the burden of paying for cleft lip and palate repair.

Left sides clefts of the lip and palate were found to be almost twice that of right sides cleft of the lip and palate. This was in keeping with reports from earlier works.

This study shows there is need for further studies in the field of cleft lip palate in all regions of the country.

Keywords:Abuja, cleft lip, cleft palate, prevalence and smile train project.
\end{abstract}

\section{Introduction}

Cleft lip and palate is a major Health problem wide.

Nigeria is the most populated black nation, the $9^{\text {th }}$ most populated country in the world with a population of over 140 million people from the result of the 2006 census figure.

The country has one of the lowest privilege rate of cleft hip and palate, 0.3 in every 1000 live births on average, through there are slight variation across the country.

The University of Abuja Teaching Hospital is a 350 bed Hospital located in Gwagwalada, a semi-urban district of the Federal Capital Territory (FCT) Abuja. It is inhabited by the Indigenes Gwari tribe, Fulani, Igbiras, Hausas, yorubas, Igbos and other tribes. The Hospital serves the people living in the district nearby states of Niger and Kogi, it is one of the referral Centers of the whole FCT.

Cleft lip and palate is under structure in the Nigerian population and places like the FCT has very scanty date on the abnormality, thus, this study attempts to established the prevalence rate of cleft lip and palate in the FCT as well as assess predisposing factors and related abnormalities.

\section{Anthropology Of The Study}

Since ancient times man was ignorant of anthropology and morphogenes his explanation for the existence of congenital abnormalities was based on a combination of religion, superstition, invention and charlatanism. The earlier trace able history of cleft lip and palate is what of horror and utter disbelief. In ancient times many congenital deformities, including the cleft lip and palate were considered to be evidence of the presence of an evil spirit in the affected child facial deformities were most condemn and the infants were "removal from the tribe or cultural unit and left to die in the surrounding wilderness" a practice that still prevails today in certain tribes in Nigeria and Africa at large.

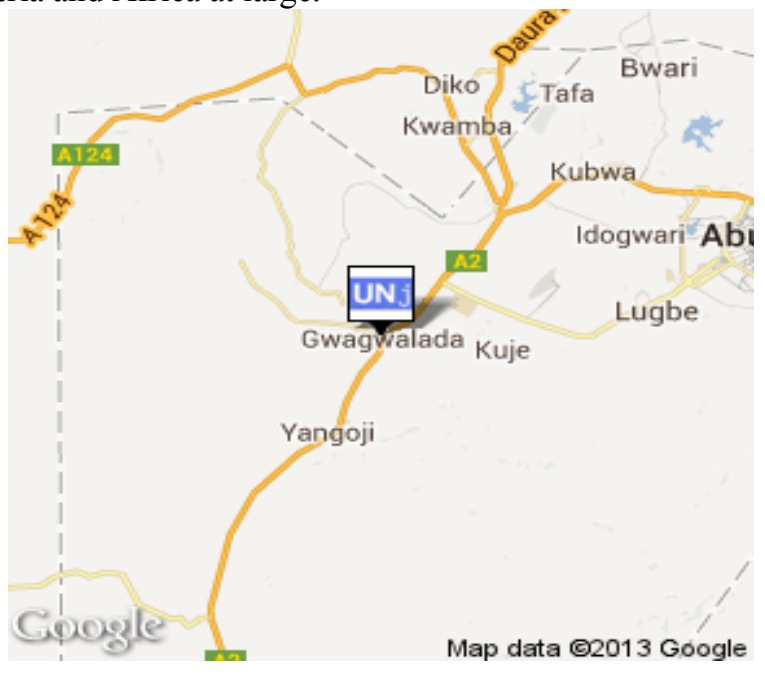




\section{Embryology Of The Palate And Lip}

Facial development in fractions typically begins with the formation of 5 primitive tissue lobes as follows.

One from the top of the level down towards the future upper lip (fronto nasal prominence lobe a.

Two from the cheeks, which meet the $1^{\text {st }}$ lobe to form the upper lip (maxillar prominence lobe $\mathrm{b} \& \mathrm{c}$ )

And just below, 2 additional lobes from the each side, which form the chin and lower lip (mandibular prominence)

If these tissue fail to meet, a gab appears where tissues could have form. This may happen in any single joining site or simultaneously in several or all of them. The resulting birth defect reflects the location of severity and individual fusion that is from a small lip or palate fissures up to a completely malformed face.

\section{Materials And Methods}

i) A customized data collection tool shown below; thistool was used to collate the records of children with cleft lip and palate born in University of Abuja Teaching Hospital.

ii) Patients registered in SOPD,POPD pediatrics ward, PNW and labour word of the Hospital

iii) Patient's folder from the medical record unit of University of Abuja Teaching Hospital.

Variables considered

Variables considered during data collection were independent variables and are as follows.

i) Bio-data of the patient and birth placement

ii) Predisposing faction which includes, maternal and paternal age, maternal drug or alcohol use during pregnancy, illness during pregnancy.

iii) Year of diagnosis and repair

\section{Data Analysis And Results}

The data were analyzed using SPSS cross tabulation and frequency distribution were also performed prevalence was calculated using the following formulation.

Prevalence rate $=\quad$ No. of cases

Total no. of PP at risk at specific period.

Total number of identified cases of cleft lip and place $\quad=\quad 42$

Total number of PP at risk $\quad=\quad 13,105$

Prevalence rate $\quad=\quad 3.2$

This prevalence rate of 3.2 in 1000 live birth (from December 2000 to December 2010) is very high as compared with values earlier reported by certain, G (1996) of 0.3 in 1, row life birth in the United State of America and 0.4 in 1000 live birth by (Iregbulem LM) in Nigeria. The study was done with records of children born on the hospital those of referred to the hospital within the given record of time. Shown in table 1 below of the 13,105 reviewed records 9114 was given birth to on the hospital while 3991 was referred. Of all these a total of 42 records were found to be diagnosed of cleft lip and palate.

VI.

Table 1: Cases by year of Diagnosis

\begin{tabular}{|l|l|l|}
\hline & Frequency & Percentage (\%) \\
\hline 2000 & 0 & 0 \\
\hline 2001 & 1 & 2.4 \\
\hline 2002 & 0 & 0 \\
\hline 2003 & 0 & 0 \\
\hline 2004 & 0 & 0 \\
\hline 2005 & 2 & 4.8 \\
\hline 2006 & 4 & 9.5 \\
\hline 2007 & 5 & 11.9 \\
\hline 2008 & 4 & 9.5 \\
\hline 2009 & 12 & 28.6 \\
\hline 2010 & 14 & 33.3 \\
\hline Total & 42 & 100.0 \\
\hline
\end{tabular}

\section{Conclusion}

The prevalence of cleft lip and palate in university of Abuja Teaching Hospital from December 2000 to December 2010 is higher than expectation in Nigeria because.

i) The Hospital serving as a referral centre for the whole of the Federal Capital Territory (Abuja and neighboring states).

ii) The smile Train Project resident in the hospital has attracted patients across the country, and thus the large number of cases. 


\section{Recommendation}

1. Further research into this is recommended in the country.

2. Good record keeping is very important.

3. Adequate enlightenment campaigns is required across the country.

\section{References}

[1]. Ross, E. A.Tale of two systems: Beliefs and prefaces of Traditional Healers concerning cleft lip and palate. Cleft palate- Cranvofalval Journal. 2007. 44:642-648.

[2]. Butali A. P. A. Mossay, epidemiology of orofacial clefts in Africa. Methodological challenges in Ascertainment. The Pan African Medical Journal 2009;2.5

[3]. Curtling, G. Primary care of the child with a chronic cur............... $2^{\text {nd }}$ edition, Saint Louis MO.CV Mosby 1996

[4]. Keating J. M. Cyclopedia of the diseases of the children. Philadelphia: Lippincott; 1889.

[5]. A very JK. Essentials of oral histology by embryology St. Louis: Mosby:1992

[6]. Mooney M, Siefel M, understanding oramiofacral anomalies: new York: wiley-Liss 2002: 3-11

[7]. E.J Curtis and Associates - genetical and environmental factions in the etiology of cleft-lip. And cleft palate cam. Dent. Association J. 1957:23:570

[8]. Harkins, C. S. et al. statistical Analysis 750cleft lip of palate patients Indian J plast org. 1962:40:70-74 